\title{
ТРАНСГРЕССИВНЫЕ СТРУКТУРЫ НИЖНЕГО РАССЛОЕННОГО ГОРИЗОНТА НА УЧАСТКЕ МАЛОСУЛЬФИДНОГО ПЛАТИНОМЕТАЛЬНОГО МЕСТОРОЖДЕНИЯ СЕВЕРНЫЙ КАМЕННИК
}

\author{
Иванов А.Н. ${ }^{1}$, Грошев Н.Ю. ${ }^{1}$, Корчагин А.У. ${ }^{2}$ \\ ${ }^{1}$ Геологический институт КНЦ РАН, Anamumbl,nikolaygroshev@gmail.com \\ ${ }^{2} \mathrm{OAO} «$ Щана», Anатить
}

Выявление на территории Кольской Арктики серии малосульфидных месторождений элементов платиновой группы (ЭПГ) является крупнейшим достижением отечественной геологии начала XXI века [4]. Малосульфидные месторождения составляют основу минерально-сырьевой базы ЭПГ в мире [6]. Начало освоения этих месторождений является делом ближайшего будущего и требует попутно с наращиванием МСБ более глубокого понимания процессов формирования рудных концентраций и их перераспределения в платиноносных рифовых толщах [1].

Процессы малосульфидного платинометального рудообразования наиболее детально изучены в рифе Меренского, Бушвельдский комплекс, ЮАР $[5,6]$. Характерной и во многом загадочной особенностью рифа, протягивающегося на многие сотни километров при средней мощности всего лишь один метр, являются так называемые «потхолы» (potholes), или рытвины, обусловленные трансгрессивно-интрузивным проникновением порции горячей рудоносной магмы в полосчатые толщи и эрозией подстилающих кумулатов (рис. 1). Трансгрессивные структуры рифа Меренского, усложняя моноклинальное залегание рудных тел и соответственно работу горнодобывающих компаний, являются предметом разносторонних исследований $[5,6]$.

Северный платинометальный риф Западно-Панского массива (ЗПМ), вмещающий несколько малосульфидных месторождений [2, 3], является ближайшим аналогом рифа Меренского на территории Кольской Арктики. Северный риф в широком смысле слова представляет собой несколько минерализованных уровней мощностью первые метры, ассоциирующих с Нижним расслоенным горизонтом (НРГ). В восточной части ЗПМ, на месторождении Киевей, этот горизонт имеет ритмично-расслоенное строение, обусловленное чередованием анортозитов, габброноритов, норитов, пироксенитов и, реже, оливиновых пород. Как правило, выделяется четыре ритма общей мощностью около 40 м, образующие нормальную фацию НРГ (рис. 2) с платинометальным оруденением в подошве всех следующих за первым ритмов. Формирование ритмов связывается с последовательным пополнением камеры рудоносным расплавом [2]. Фациальные вариации НРГ в пределах месторождения Киевей ограничиваются выклиниванием третьего и последующих ритмов, при вы-

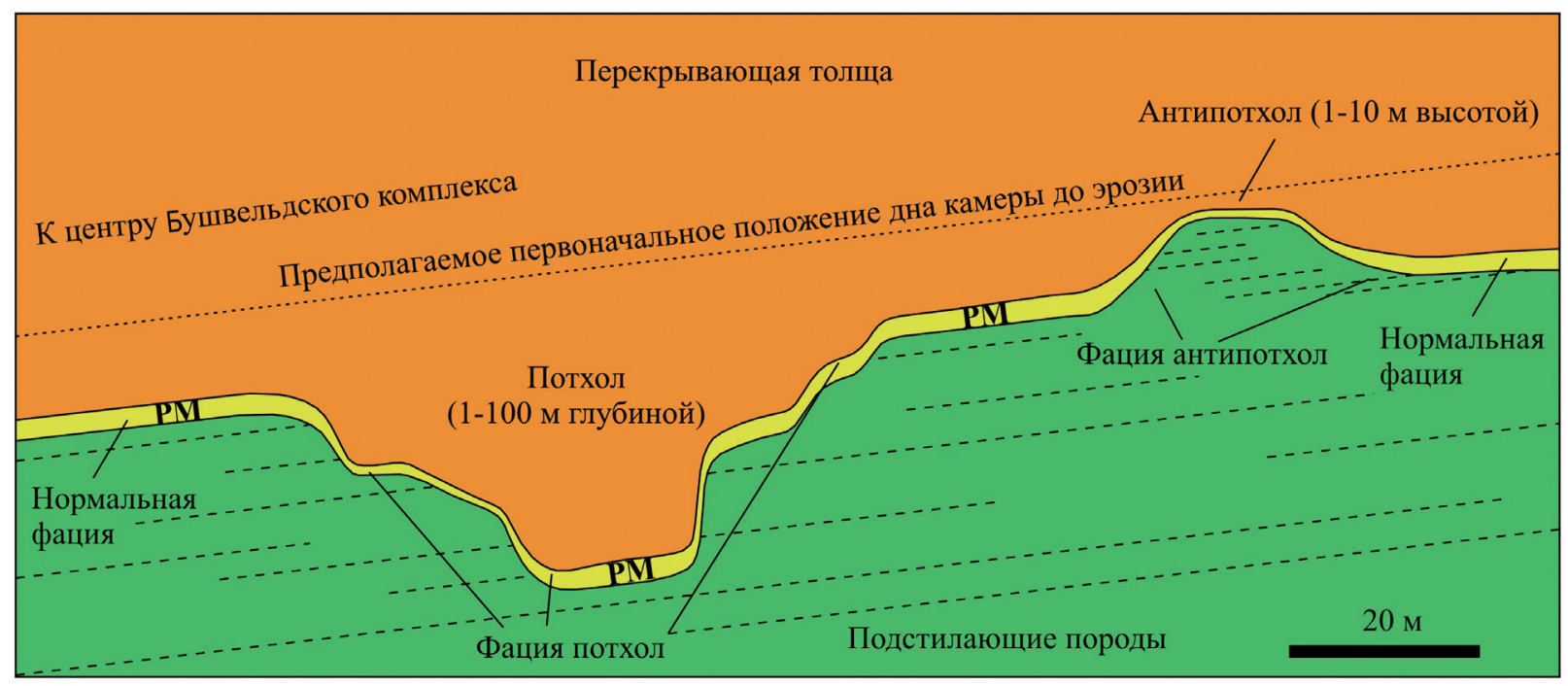

Рис. 1. Схематичный обобщенный разрез, иллюстрирующий трансгрессивные взаимоотношения рифа Меренского (РМ) с подстилающими породами, с изменениями по [5]. 


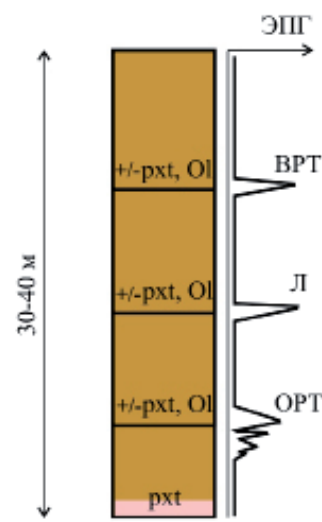

Нормальная фация (месторождение Киевей)
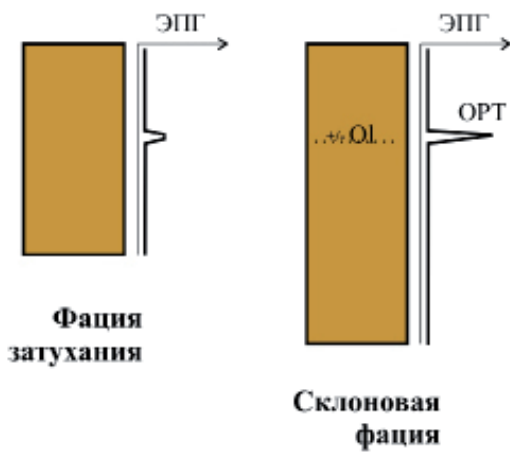

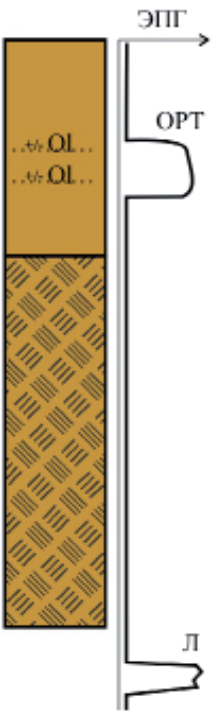

Русловая фация

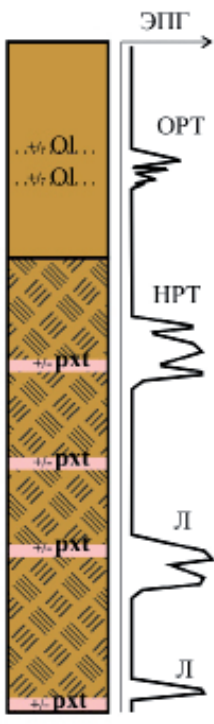

Полная русловая фация

Рис. 2. Ряд геологических фаций Нижнего расслоенного горизонта на западном участке месторождения Северный Каменник в сравнении с месторождением Киевей. Коричневым показаны габбронориты, лейкогаббро и анортозиты, розовым - пироксениты; штриховкой - такситовые до пегматоидных габбронориты. Сокращения: ВРТ - верхнее рудное тело, ОРТ - основное рудное тело, НРТ - нижнее рудное тело, Л - линза, $\mathrm{Ol}$ - оливин, pxt - среднезернистый пироксенит, +/- pxt - пегматоидный пироксенит.

держанном по простиранию и падению основном рудном теле и его моноклинальном залегании с падением на юг под углом $30^{\circ}$.

При разведке месторождения Северный Каменник [3] на западном фланге Северного рифа, вблизи предполагаемого питающего магматического канала, были установлены широкие вариации углов падения основного рудного тела (от $25^{\circ}$ до $50^{\circ}$ ) и геологических фаций НРГ (от фации затухания до полной русловой фации; рис. 2 и 3). Эти вариации сопровождаются многочисленными случаями выклинивания рудного тела (рис. 4, а). В отличие от месторождения Киевей, на Северном Каменнике увеличение разнообразия фаций происходит вниз по разрезу от основного рудного тела и обусловлено появлением ниже него толщи такситовых габброноритов (рис. 3), вероятно, перекристаллизованных. Необходимо отметить, что в случае полной русловой фации в этой толще залегает платинометалльная сульфидная минерализация, которая по своим геохимическим свойствам отличается от основного оруденения: отношение $\mathrm{Pd} / \mathrm{Pt}$ варьирует в широких пределах, $\mathrm{Cu} / \mathrm{Ni}$ увеличивается вниз по разрезу, сульфиды обогащаются ЭПГ. В некоторых скважинах отмечается до четырех геолого-геохимических типов оруденения (рис. 3).

Перечисленные особенности НРГ на участке Северный Каменник вместе с отсутствием базального кумулятивного норит-пироксенитового слоя, развитого почти повсеместно в нормальных фациях НРГ (рис. 2), свидетельствуют о высокой подвижности поступившей вновь магмы на этом участке рифа. Движущаяся горячая магма, прогревая, эродируя и частично расплавляя подстилающие породы, выработала в них углубления, напоминающие русла потоков (рис. 4) или потхолы рифа Меренского (рис. 1). Предположительно, впоследствии углубления были заполнены кристаллической кашей, на которую продолжал воздействовать поток более поздних рудоносных магматических импульсов. В конечном счете, это приводило к перекристаллизации первичных кумулатов с образованием такситовых текстур и пегматоидов (рис. 2), дифференциации мигрирующего вниз сульфидного расплава (см. типы оруденения) и его просачиванию, в том числе, ниже подошвы НРГ (рис. 3).

Распределение склоновой и русловых фаций НРГ, образующих углубления в нижележащих кумулатах (рис. 4, б), в большинстве случаев соответствует распространению кондиционных руд основного рудного тела (рис. 4, a). Таким образом, явно развитые трансгрессивные структу- 


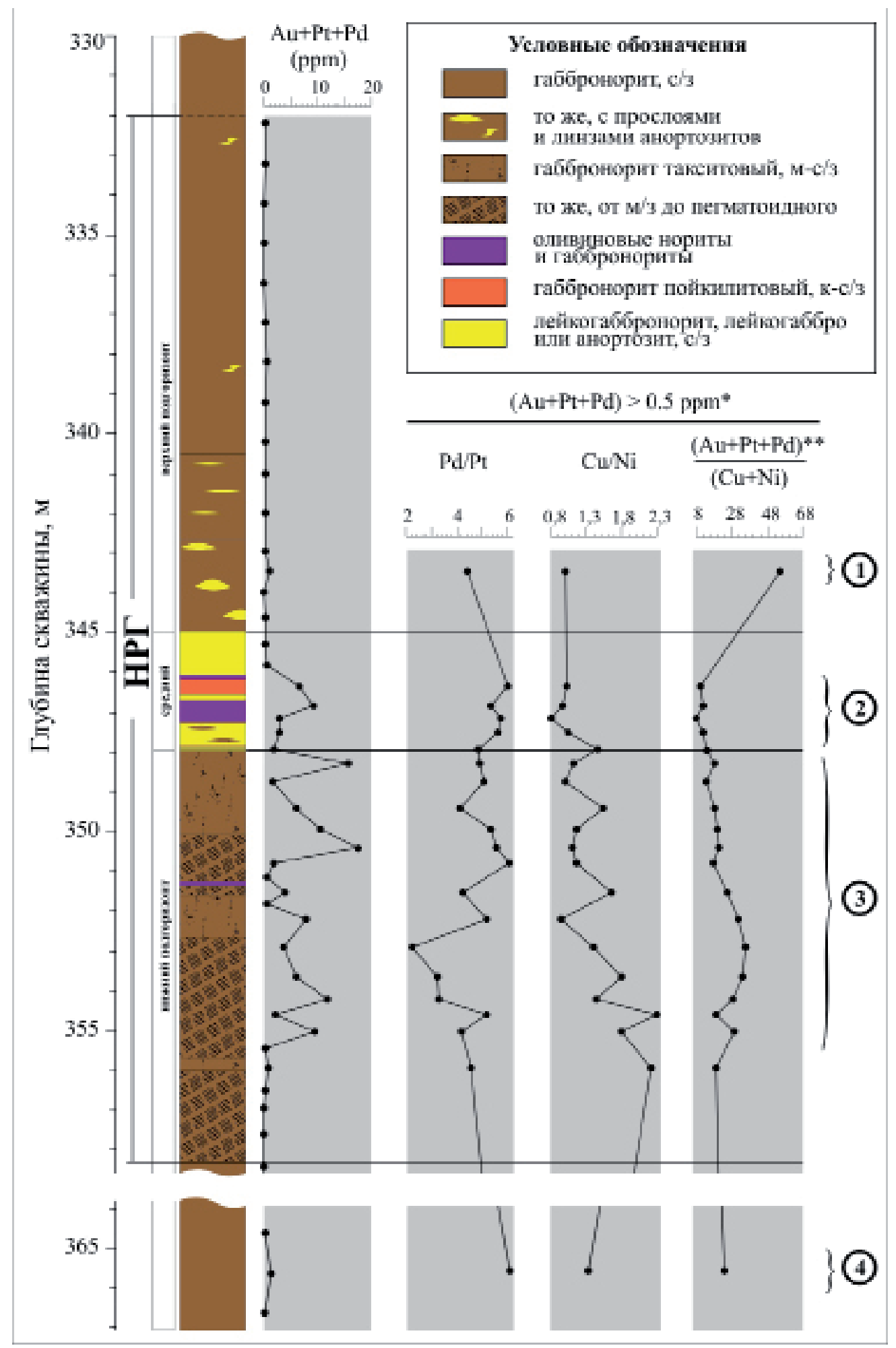

Рис. 3. Фрагмент геологической колонки по скважине BG-N-126, пересекшей полную русловую фацию НРГ в западном рудном объекте месторождения Северный Каменник [2].

Сокращения: м/3 - мелкозернистый, м-с/3 - мелко-среднезернистый, с/3 - среднезернистый, к-с/3 - крупносреднезернистый. Цифры в кружках обозначают геолого-геохимические типы платинометального оруденения. * - условие расчета отношений концентраций металлов, ** - $\mathrm{Au}+\mathrm{Pt}+\mathrm{Pd}$ в ppm, $\mathrm{Cu}+\mathrm{Ni}$ в мac. \%. $\mathrm{Au}, \mathrm{Pt}, \mathrm{Pd}$, $\mathrm{Cu}, \mathrm{Ni}$ определены методом атомно-эмиссионной спектрометрии с индуктивно-связанной плазмой («Стюарт Геокемикл энд Эссей», г. Москва). 

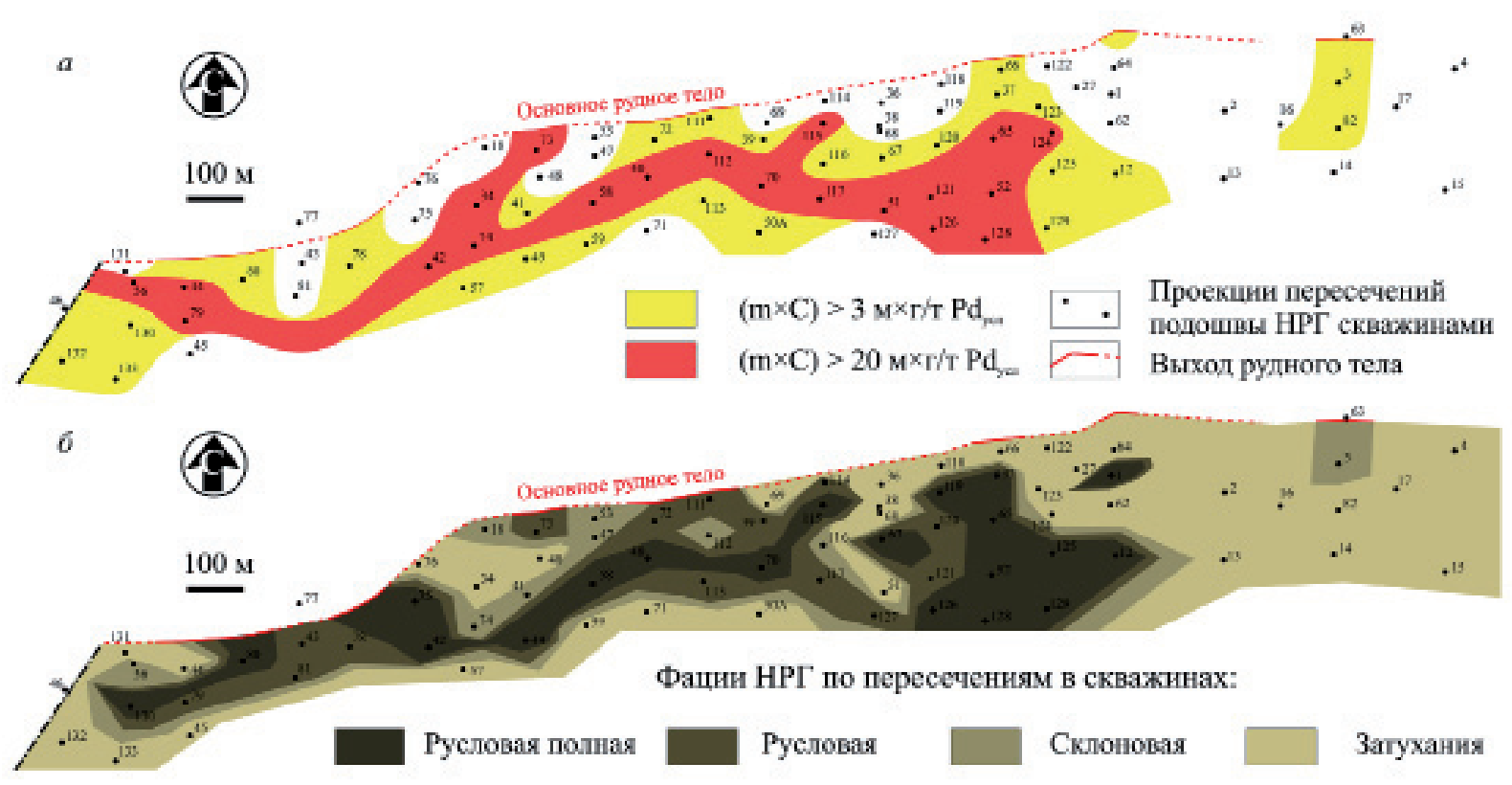

Рис. 4. $a$ - Проекция основного рудного тела западного объекта месторождения Северный Каменник на горизонтальную плоскость при бортовом содержании $\mathrm{Pd}_{\text {усл }} 3$ г/т до глубины 250 м [3]. б - Распределение фаций НРГ в той же проекции.

ры НРГ, устроенные подобно потхолам рифа Меренского аккумулируют в себе, по-видимому, большую часть платинометального оруденения одного из участков месторождения Северный Каменник. В связи с этим для создания петрогенетической модели месторождения необходимо предпринять детальное изучение разрезов выделенных фаций по представительным скважинам этого участка.

Работа выполнена в рамках темы НИР №0231-2015-0002 и частично поддержана из средств РФФИ (16-05-00367, 15-35-20501).

\section{Литература}

1. Додин Д.А., Чернышов Н.М., Чередникова О.И. Металлогения платиноидов крупных регионов России. М.: Геоинформмарк. 2001.302 с.

2. Корчагин А.У. и др. Платинометалльное месторождение Киевей в Западно-Панском расслоенном массиве: геологическое строение и состав оруденения / Стратегические минеральные ресурсы Лапландии - основы устойчивого развития Севера. Апатиты: Изд-во КНЦ РАН. 2009. С. 12-32.

3. Корчагин А.У. и др. Геология и вещественный состав руд малосульфидного платинометального месторождения Северный Каменник в Западно-Панском массиве (Кольский полуостров, Россия) // Руды и металлы. 2016. № 1. С. 42-51.

4. Митрофанов Ф.П. и др. Восточно-Скандинавская и Норильская плюмовые базитовые обширные изверженные провинции Pt-Pd руд: геологическое и металлогеническое сопоставление // Геология рудных месторождений. 2013. 55(5). С. 357-373.

5. Latypov R., Chistyakova S., Page A., Hornsey R. Field evidence for the in situ crystallization of the Merensky Reef // Journal of Petrology. 2015. 56(12). P. 2341-2372.

6. Naldrett A.J. Magmatic sulfide deposits: Geology, geochemistry and exploration. Springer Science \& Business Media. 2013. 727 p. 